\title{
Enantioselective Organocatalyzed Desymmetrization of 3-Substi- tuted Cyclobutanones through Michael Addition to Nitroalkenes
}

\author{
Francesca Capitta a,b \\ Angelo Frongia ${ }^{a}$ \\ Jean Ollivier*b \\ David J. Aitken ${ }^{b}$ \\ Francesco Secci*a \\ Pier Paolo Piras ${ }^{a}$ \\ Régis Guillot ${ }^{b}$ \\ a Dipartimento di Scienze Chimiche, Università di Cagliari, Complesso Universitario di Monserrato, \\ S.S. 554, Bivio per Sestu, 09042 Monserrato (Cagliari), Italy \\ fsecci@unica.it \\ b CP3A Organic Synthesis Group, Institut de Chimie Moléculaire et des Matériaux d'Orsay - \\ ICMMO (CNRS UMR 8182), Université Paris-Sud, 15 rue Georges Clémenceau, 91405 Orsay cedex, \\ France
}


major stereoisomer $63-86 \%, 53-88 \%$ ee

\author{
Received: 11.09.2014 \\ Accepted after revision: 13.10 .2014 \\ Published online: 11.11 .2014 \\ DOI: 10.1055/s-0034-1379489; Art ID: st-2014-d0757-I
}

Abstract A new procedure for the desymmetrization of prochiral 3-substituted cyclobutanones has been established through organocatalyzed Michael addition to nitroalkenes. The approach provides enantiomerically enriched 2-alkyl-3-aryl(alkyl) cyclobutanones with three contiguous stereogenic centers. The optimum conditions were determined by screening of catalyst and reaction conditions and a transitionstate model is proposed to account for the observed diastereomeric and enantiomeric selectivities.

Keywords cyclobutanones, Michael addition, nitroalkenes, organocatalysis, stereoselectivity

Cyclobutanones represent a family of stable yet chemically reactive functionalized small-ring molecules that have potential value as intermediates for the enantioselective synthesis of natural products and therapeutically relevant compounds. ${ }^{1}$ In parallel with our studies on organocatalyzed transformations of 2-hydroxycyclobutanone, such as aldolization $^{2}$ and $\alpha$-aminocyclobutanone synthesis, ${ }^{3}$ we have also shown that the organocatalyzed aldolization of 3 substituted cyclobutanones can be conducted to provide aldol adducts with high enantio- and diastereoselectivities; ${ }^{4}$ whereas ring-expanded products were obtained in organocatalyzed reactions with nitrosobenzene. ${ }^{5}$ To explore the scope of organocatalyzed desymmetrizations of 3-substituted cyclobutanones, we undertook an investigation of the Michael addition reaction with nitroalkenes to establish a comparatively gentle way to perform such chemical transformations without disturbing the strained ring and to yield products with high selectivities.

First, a catalyst screening was performed by using the Michael addition reaction of 3-tolylcyclobutanone (1a) with trans- $\beta$-nitrostyrene (2a) as the model transformation. L-Proline (I) and two of its derivatives II and III, were investigated, along with Jacobsen thiourea derivative ${ }^{6}$ IV, and two squaramide derivatives $\mathbf{V a}$ and $\mathbf{V b}$, which have also proven to be useful bifunctional organocatalysts. ${ }^{7}$ The model reaction was performed in different solvents at room temperature for two or four days in the presence of 10,20 , or $30 \%$ organocatalyst; the results are presented in Table 1 .

The general trend was for the formation of the expected Michael adduct 3a as a mixture of only two diastereomers, which were isolated in an acceptable yield in most cases.

The major stereoisomer was the same in every case, as confirmed by NMR analysis and by the dextrorotatory optical rotation, with the single exception of the reaction conducted in DMSO in the presence of proline sulfonamide II, which gave a slight preference for the opposite antipode (Table 1, entry 2). Reactions carried out in DMSO in the presence of catalysts I, II, and III gave acceptable yields after two days, and were promising in terms of diastereoselectivity but disappointing with respect to enantioselectivity (entries 1-3). When catalyst IV was used at $10 \mathrm{~mol} \%$ over two days, reactions were more encouraging in terms of the ee values of the major diastereomer; however, the yields of adduct 3a were low when the reaction was carried out either without solvent (entry 4 ) or in a number of solvents of varying polarity ( $n$-hexane, acetonitrile, THF, DMF; entries $5-8$ ). A better yield and a significant enantiomeric excess were obtained when the reaction was performed in chloroform (entry 9), but the highest ee value combined with an excellent diastereomeric ratio were observed in toluene (entry 10). Frustratingly, however, the yield of 3a was low, and only a modest increase was observed with higher (20 or $30 \mathrm{~mol} \%$ ) catalyst loading (entries 11 and 12 ). Surprisingly, the yield improved significantly when the model reaction in the presence of $10 \mathrm{~mol} \%$ IV was continued in toluene for four days (entry 13). Only a slight loss of diastereo- and enantioselectivities was observed under these conditions. 
Table 1 Catalyst and Solvent Screening for the Model Nitro-Michael Addition Reaction of 3-(4-Tolyl)cyclobutanone Using Catalysts (S)-I-III, IV, Va, and Vb<smiles>Cc1ccc(C2CC(=O)C2)cc1</smiles>
$1 a$
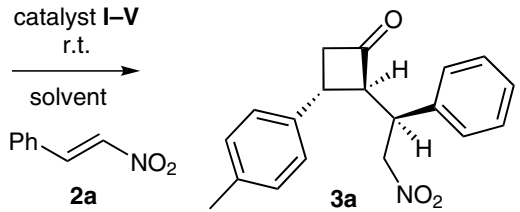<smiles>O=C(O)C1CCCN1</smiles><smiles>O=C(NS(=O)(=O)c1ccccc1)C1CCCN1</smiles><smiles>C1CNC(c2nnn[nH]2)C1</smiles><smiles>CNC(=S)N[C@@H](C(=O)N(C)Cc1ccccc1)C(C)(C)C</smiles>

IV<smiles>CCCCCCC(N)CCC</smiles>

Va $\mathrm{n}=0$

Vb $n=1$

\begin{tabular}{lllllll}
\hline $\begin{array}{l}\text { Entry } \\
\begin{array}{l}\text { Cat. } \\
\text { (mol\%) }\end{array}\end{array}$ & $\begin{array}{l}\text { Time } \\
\text { (h) }\end{array}$ & Solvent & $\begin{array}{l}\text { Yield } \\
(\%)\end{array}$ & $\begin{array}{l}\mathrm{dr}(\%) \\
\text { major/minor }\end{array}$ & $\begin{array}{l}\text { ee (\%) major } \\
\text { diastereoisomer }\end{array}$ \\
\hline 1 & $\mathbf{I}(20)$ & 48 & DMSO & 68 & $87: 13$ & 6 \\
2 & $\mathbf{I I}(20)$ & 48 & DMSO & 42 & $93: 7$ & -10 \\
3 & $\mathbf{I I I}(20)$ & 48 & DMSO & 93 & $90: 10$ & 10 \\
4 & $\mathbf{I V}(10)$ & 48 & DMSO & 10 & $80: 20$ & 64 \\
5 & $\mathbf{I V}(10)$ & 48 & neat & 13 & $83: 17$ & nd \\
6 & $\mathbf{I V}(10)$ & 48 & n-hexane & 17 & $86: 14$ & 40 \\
7 & $\mathbf{I V}(10)$ & 48 & CH ${ }_{3} \mathrm{CN}$ & 41 & $99: 1$ & 78 \\
8 & $\mathbf{I V}(10)$ & 48 & THF & 28 & $80: 20$ & nd \\
9 & $\mathbf{I V}(10)$ & 48 & DMF & 72 & $80: 20$ & 74 \\
10 & $\mathbf{I V}(10)$ & 48 & CHCl & 29 & $96: 4$ & 88 \\
11 & $\mathbf{I V}(20)$ & 48 & toluene & 41 & $80: 20$ & 38 \\
12 & $\mathbf{I V}(30)$ & 48 & toluene & 52 & $90: 10$ & 20 \\
13 & $\mathbf{I V}(10)$ & 96 & toluene & 76 & $80: 20$ & 74 \\
14 & $\mathbf{V}(20)$ & 96 & toluene & 24 & $80: 20$ & nd \\
15 & $\mathbf{V}(20)$ & 96 & toluene & 18 & $75: 25$ & nd \\
\hline
\end{tabular}

Finally, the reactions performed in toluene in the presence of squaramides $\mathbf{V a}$ and $\mathbf{~ V b}$ gave only low yields of 3a (entries 14 and 15). Based on these results, the conditions retained for the investigation of the reaction scope were 10 mol\% catalyst IV in toluene for four days. We applied these conditions to the reaction of a range of 3-substituted cyclobutanones $\mathbf{1 b}-\mathbf{g}$ with trans- $\beta$-nitrostyrene $\mathbf{2 a}$ (Table 2 ). The reactions of the three alkylated derivatives $\mathbf{1 b}$-d furnished the expected adducts with good yields, reasonable diastereoselectivities, and rather modest enantioselectivities (entries 1-3).
The three arylated derivatives $\mathbf{1 e - g}$ provided results that were comparable to those obtained with 3-(4-tolyl)cyclobutanone 1a (Table 2, entries 5-7). This study demonstrates the generality of the Michael reaction of a range 3substituted cyclobutanones in which the general selectivity trend is retained. To complement this study, it was appropriate to evaluate the reactivity of other nitroalkene derivatives. To this end, the Michael reaction was carried out by using 3-(4-tolyl)cyclobutanone (1a) and a selection of diversely substituted nitrostyrenes. As shown in Table 3, under standard conditions (catalyst IV, toluene, room temperature, $96 \mathrm{~h}$ ), the aryl-substituted nitrostyrenes $\mathbf{2 b - d}$ (entries 1-3) underwent Michael addition with 1a to give expected products with yields up to $66 \%$, relatively good diastereoselectivity, and an enantioselectivity in the range 47-73\%. Furthermore, the reaction performed with 4-anisylnitroethylene (2e; entry 4 ) led to the expected product with good yield and diastereoselectivity; however, the major diastereomer was obtained with a significantly lower enantioselectivity.

To rationalize the formation of one major diastereomer, information was required concerning its absolute configuration. Chromatographic separation of diastereoisomers of $\mathbf{3}$ was generally inadequate; however, when a solution of $\mathbf{3 g}$ (Table 2) in diethyl ether/petroleum ether (1:5) was allowed to stand, slow evaporation of the solvent induced some precipitation. NMR analysis of the solid showed that it corresponded to the single major diastereomer of $\mathbf{3 g}$, which was then recrystallized from EtOH and the structure was analyzed by X-ray diffraction ${ }^{8}$ (Figure 1 ). The molecular structure exhibited atranssubstitution geometry on the cyclobutanone ring with an $(R, R)$ configuration, which should be applicable for all the aromatic cyclobutanone derivatives $\mathbf{3 e}-\mathbf{g}$ and $\mathbf{4 b}$-e exhibiting also an $S$-configuration at the exocyclic stereocenter. By comparison of the coupling con-

Table 2 Nitro-Michael Addition Reaction of 3-Substituted Cyclobutanones $\mathbf{1} \mathbf{b}-\mathbf{g}$ to trans- $\beta$-Nitrostirene $\mathbf{2} \mathbf{a}$ Using Catalyst IV

\begin{tabular}{|c|c|c|c|c|c|}
\hline & $1 b-$ & to & ene, r.t & $\overrightarrow{96 \mathrm{~h}}$ & ${ }_{.}^{\mathrm{O}} \mathrm{H}$ \\
\hline Entry & 1 & $\mathrm{R}$ & $\begin{array}{l}\text { Yield } \\
(\%)\end{array}$ & $\begin{array}{l}\mathrm{dr}(\%) \\
\text { major/minor }\end{array}$ & $\begin{array}{l}\text { ee }(\%) \text { major } \\
\text { diastereoisomer }\end{array}$ \\
\hline 1 & $1 b$ & $\mathrm{C}_{6} \mathrm{H}_{13}$ & 70 & $90: 10$ & 53 \\
\hline 2 & $1 c$ & $\mathrm{C}_{6} \mathrm{H}_{11}$ & 63 & $80: 20$ & 59 \\
\hline 3 & 1d & $\mathrm{PhCH}_{2} \mathrm{CH}_{2}$ & 60 & $77: 23$ & 71 \\
\hline 4 & $1 e$ & $\mathrm{Ph}$ & 63 & $66: 34$ & 51 \\
\hline 5 & $1 f$ & $4-\mathrm{ClC}_{6} \mathrm{H}_{4}$ & 86 & $66: 34$ & 64 \\
\hline 6 & $1 \mathrm{~g}$ & $4-\mathrm{BrC}_{6} \mathrm{H}_{4}$ & 83 & $77: 23$ & 64 \\
\hline
\end{tabular}


Table 3 Organocatalyzed Nitro-Michael Addition of Cyclobutanone 1a to Aryl Substituted trans- $\beta$-Nitroalkenes $\mathbf{2 b}$-e Using Catalyst IV

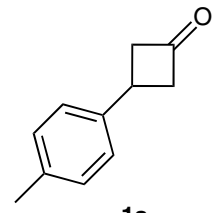

1 a

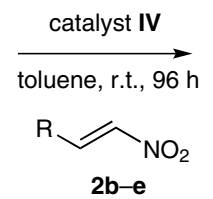

$2 b-e$



$4 b-e$

\begin{tabular}{lllccl}
\hline Entry & Nitrostyrene 2 & R & $\begin{array}{l}\text { Yield } \\
(\%)\end{array}$ & $\begin{array}{l}\mathrm{dr}(\%) \text { ma- } \\
\text { jor/minor }\end{array}$ & $\begin{array}{l}\text { ee (\%) major } \\
\text { diastereoisomer }\end{array}$ \\
\hline 1 & 2b & $4-\mathrm{FC}_{6} \mathrm{H}_{4}$ & 76 & $81: 19$ & 47 \\
2 & 2c & $2,4-\mathrm{Cl}_{2} \mathrm{C}_{6} \mathrm{H}_{3}$ & 86 & $81: 19$ & 51 \\
3 & 2d & $\mathrm{PhCH}_{2} \mathrm{CH}_{2}$ & 66 & $73: 27$ & 73 \\
4 & 2e & $4-\mathrm{MeOC}_{6} \mathrm{H}_{4}$ & 79 & $85: 15$ & 25 \\
\hline
\end{tabular}

stants between the protons at the cyclobutanone 2- and 3positions in the NMR spectrum of the mixture of the two diastereomers of $\mathbf{3 g}$, it was concluded that the minor diastereomer also possessed atransring substitution pattern, although further information on its configuration was not acquired. Given the similarities in physicochemical and spectroscopic behavior of all samples of adducts $\mathbf{3 a}-\mathbf{g}$, it is proposed by extension that the same major configuration pattern prevails throughout the series (although the $R$ and $S$ descriptors may vary with the identity of the ring substituents).
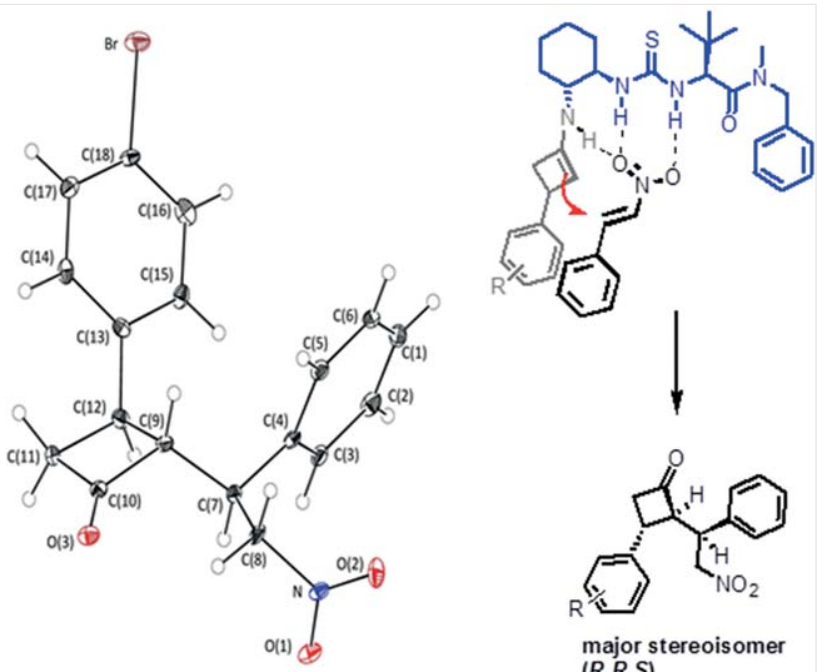

Figure 1 (a) ORTEP plot of X-ray crystal structure of the major diastereomer of cyclobutanone $\mathbf{3 g}$. (b) Plausible transition-state model for the Michael formation of the major stereoisomers of cyclobutanones $\mathbf{3}$ (generic aryl substituents are used for illustration)

By using the recent work by Rodriguez ${ }^{9}$ as a lead, it is possible to suggest an explanation for the origins of the stereoselectivity in our reactions, taking into account both the geometry of the catalyst and the hydrogen bonding features of the catalyst-enamine intermediate. It is proposed that the preferred alignment of the nitroalkene is that shown in Figure 1, which brings the reacting centers into proximity while minimizing steric repulsion. In this orientation, nucleophilic attack of the enamine at the electrophilic center followed by cleavage of the carbonyl would give the adduct with an $R, R, S$-configuration.

In summary, we have examined the Michael addition reaction as a new way of achieving organocatalyzed enantioselective desymmetrization of 3-substituted cyclobutanones. Of the possible diastereomers, one was formed predominantly and reproducibly over a range of substrate examples. A plausible transition-state model is proposed to explain the origins of the selectivity. This stereoselective transformation further underlines the value of cyclobutanones as building blocks for fine organic synthesis, and provides access to materials bearing three contiguous stereocenters in enantioenriched form. ${ }^{10}$

\section{Supporting Information}

Supporting information for this article is available online at http://dx.doi.org/10.1055/s-0034-1379489.

\section{References and Notes}

(1) (a) Honda, T. J. Synth. Org. Chem., Jpn. 2002, 60, 1104. (b) Nemoto, H.; Fukumoto, K. Synlett 1997, 863. (c) Nemoto, H.; Tanabe, T.; Fukumoto, K. Tennen Yuki Kagobutsu Toronkai Koen Yoshishu 1998, 40, 703. (d) Weinges, K.; Schmidbauer, S.; Schick, H. Chem. Ber. 1994, 127, 1305. (e) Nemoto, H.; Hishibashi, H.; Nagamochi, M.; Fukumoto, K. J. Org. Chem. 1992, 57, 1707. (f) Secci, F.; Frongia, A.; Piras, P. P. Molecules 2013, 18, 15541.

(2) (a) Aitken, D. J.; Capitta, F.; Frongia, A.; Gori, D.; Guillot, R.; Ollivier, J.; Piras, P. P.; Secci, F.; Spiga, M. Synlett 2011, 712. (b) Aitken, D. J.; Capitta, F.; Frongia, A.; Ollivier, J.; Piras, P. P.; Secci, F. Synlett 2012, 727.

(3) (a) Aitken, D. J.; Caboni, P.; Eijsberg, H.; Frongia, A.; Guillot, R.; Ollivier, J.; Piras, P. P.; Secci, F. Adv. Synth. Catal. 2014, 356, 941. (b) Frongia, A.; Melis, N.; Serra, I.; Secci, F.; Piras, P. P.; Caboni, P. Asian J. Org. Chem. 2014, 3, 378. (c) Secci, F.; Frongia, A.; Rubanu, M. G.; Sechi, M. L.; Sarais, G.; Arca, M.; Piras, P. P. Eur. J. Org. Chem. 2014, 6659.

(4) Aitken, D. J.; Bernard, A. M.; Capitta, F.; Frongia, A.; Guillot, R.; Ollivier, J.; Piras, P. P.; Secci, F.; Spiga, M. Org. Biomol. Chem. 2012, 10, 5045.

(5) Capitta, F.; Frongia, A.; Ollivier, J.; Piras, P. P.; Secci, F. Synlett 2011, 89.

(6) Wenzel, A.; Jacobsen, E. N. J. Am. Chem. Soc. 2002, 124, 12964.

(7) (a) Malerich, J. P.; Hagihara, K.; Rawal, V. H. J. Am. Chem. Soc. 2008, 130, 14416. (b) Konishi, H.; Lam, T. Y.; Rawal, V. H. Org. Lett. 2010, 12, 2028.

(8) CCDC 1009271 contains the supplementary crystallographic data for the major stereoisomer of cyclobutanone $3 g$. These data can be obtained free of charge from the Cambridge Crystallographic Data Centre at http://www.ccdc.cam.ac.uk/Community/Requestastructure. 
(9) (a) Du, H.; Rodriguez, J.; Bugaut, X.; Constantieux, T. Chem. Eur. J. 2014, 20, 8458. (b) Mailhol, D.; del Mar Sanchez Duque, M.; Raimondi, W.; Bonne, D.; Constantieux, T.; Coquerel, Y.; Rodriguez, J. Adv. Synth. Catal. 2012, 354, 3523.

(10) Desymmetrization of 3-Substituted Cyclobutanones through Michael Addition to Nitroalkenes; Typical Procedure for 2(2-Nitro-1-phenylethyl)-3-(4-tolyl)cyclobutanone (3a): A solution of cyclobutanone 1a (216 mg, $1.3 \mathrm{mmol}), \beta$-nitrostyrene $2 \mathrm{a}(0.387 \mathrm{mg}, 2.6 \mathrm{mmol})$ and catalyst IV ( $10 \mathrm{~mol} \%, 17.7 \mathrm{mg}$, $0.13 \mathrm{mmol})$ in anhydrous toluene $(0.8 \mathrm{~mL})$ was stirred at room temperature for $96 \mathrm{~h}$. The reaction mixture was loaded directly onto a silica flash chromatography column and eluted with hexane- $\mathrm{Et}_{2} \mathrm{O}$ (90:10 to $\left.1: 1\right)$ to afford the corresponding pure nitroalkyl cyclobutanone $3 a$ as a 80:20 diastereoisomeric mixture (ee major 74\%). Yield: 76\%; yellow oil; $[\alpha]_{D}{ }^{29}-24.1$ (c 0.1, $\mathrm{CHCl}_{3}$ ). IR (film): $3030,1777 \mathrm{~cm}^{-1}$. ${ }^{1} \mathrm{H}$ NMR $(500 \mathrm{MHz}$, $\left.\mathrm{CDCl}_{3}\right): \delta=2.26(\mathrm{~s}, 3 \mathrm{H}), 3.19-3.37(\mathrm{~m}, 3 \mathrm{H}), 3.53-3.57(\mathrm{~m}, 1 \mathrm{H})$, 3.82-3.87 (m, $1 \mathrm{H}), 4.62-4.67(\mathrm{~m}, 1 \mathrm{H}), 5.05$ (dd, $J=13.0,5.0 \mathrm{~Hz}$, $1 \mathrm{H}), 6.72(\mathrm{~d}, J=8.0 \mathrm{~Hz}, 2 \mathrm{H}), 6.97(\mathrm{~d}, J=8.0 \mathrm{~Hz}, 2 \mathrm{H}), 7.09-7.11$ $(\mathrm{m}, 2 \mathrm{H}), 7.22-7.24(\mathrm{~m}, 3 \mathrm{H}) .{ }^{13} \mathrm{C}$ NMR $\left(125 \mathrm{MHz}, \mathrm{CDCl}_{3}\right): \delta=$ 20.9, 34.7, 44.6, 51.5, 68.9, 77.7, 110.0, 110.3, 126.1, 127.9, 128.1, 128.9, 129.1, 129.6, 136.2, 136.4, 138.5, 206.7. MS (ESI): $\mathrm{m} / z$ [M + Na] calcd. for $\mathrm{C}_{19} \mathrm{H}_{19} \mathrm{NO}_{3} \mathrm{Na}$ : 332.1263; found: 332.1264. Chiral-phase HPLC [Daicel Chiralcel AD-H column; hexane- $i$-PrOH (95:5); flow rate $=1.0 \mathrm{~mL} / \mathrm{min} ; \lambda=254 \mathrm{~nm}$ ]: ee $=74 \% ; t_{R}=13.9$ (major), 16.7 (minor) $\mathrm{min}$. 